\title{
Optimization of ionic concentrations in engineered water injection in carbonate reservoir through ANN and FGA
}

\author{
Leonardo Fonseca Reginato ${ }^{1, *}$, Lucas Gomes Pedroni ${ }^{2}$, André Luiz Martins Compan ${ }^{2}$, Rodrigo Skinner ${ }^{2}$, \\ and Marcio Augusto Sampaio ${ }^{1}$ \\ ${ }^{1}$ Departamento de Engenharia de Minas e de Petróleo, Escola Politécnica, Universidade de São Paulo, Santos, SP 11013-560, Brasil
${ }^{2}$ Centro de Pesquisas Leopoldo Américo Miguez de Mello (CENPES), Petrobras S.A., Rio de Janeiro, RJ 21941-915, Brasil
}

Received: 22 September 2020 / Accepted: 7 December 2020

\begin{abstract}
Engineered Water Injection (EWI) has been increasingly tested and applied to enhance fluid displacement in reservoirs. The modification of ionic concentration provides interactions with the pore wall, which facilitates the oil mobility. This mechanism in carbonates alters the natural rock wettability being quite an attractive recovery method. Currently, numerical simulation with this injection method remains limited to simplified models based on experimental data. Therefore, this study uses Artificial Neural Networks (ANN) learnability to incorporate the analytical correlation between the ionic combination and the relative permeability $(\mathrm{Kr})$, which depicts the wettability alteration. The ionic composition in the injection system of a Brazilian Pre-Salt benchmark is optimized to maximize the Net Present Value (NPV) of the field. The optimization results indicate the EWI to be the most profitable method for the cases tested. EWI also increased oil recovery by about $8.7 \%$ with the same injected amount and reduced the accumulated water production around $52 \%$, compared to the common water injection.
\end{abstract}

\section{Introduction}

Reservoir engineering seeks to manage the entire productive life of the field. This requires using computational tools to find the best strategy and to guarantee the highest Net Present Value (NPV). Its simulation requires parameters, such as physical, chemical, petrophysical, extension, localization, and architecture. Thus, knowing these conditions and considering economic scenarios, it is possible to decide on a better oil recovery method.

These numerical models seek to be the best real reservoir representation, but often some information is disregarded to enable the simulation, which generates unreliable forecasting data to outline a successful strategy in the production of this field. According to Fabbri et al. (2020), one solution is to calibrate the simulation with experimental work, but this can provide an increase in computational effort. Thus, it is ideal to use simulation tools that preserve its real characteristics, especially when combined with advanced production methods (Breitenbach, 1991; Dake, 2015; Lie, 2012; Mustafiz and Islam, 2008).

Some oil recovery methods have gained attention, such as Low Salinity Water Injection (also called Smart Waterflood (Saudi Aramco), Designer Water (Shell), LoSal (British Petroleum), and Advanced Ion Management

* Corresponding author: leonardofonseca.r@usp.br
$($ ExxonMobil)). In general terms, Low Salinity Water Injection (LSWI) is an enhanced technique in which the ionic concentration control of injected water results in additional oil recovery of the field (Dang et al., 2015). After intensive laboratory research and field-scale tests with LSWI achieve positive responses, the method is currently accepted and applied by major oil companies worldwide (Zhang et al., 2020).

This technique appears in one of the first surveys by Bernard (1967), who observed a different oil recovery in the tested samples, just varying the injected brine composition. The author hypothesizes that this effect happens in the interaction with freshwater and hydratable clay present in sandstone samples. In 1998, Morrow et al. quantified the influence of brine composition in the wettability properties, using the spontaneous imbibition core test, beginning the discussion on a multi-effect occurring during the water, oil, and rock interaction.

Other works confirm the LSWI as an appropriate application in carbonate reservoirs, in which the main effect reported was the reduction of the polar bond between carboxylic compounds and rock minerals, increasing the pore wall water adsorption (Fathi et al., 2011; Strand et al., 2006; Yousef et al., 2010; Zhang et al., 2007). Therefore, the control of potential ions $\left(\mathrm{SO}_{4}{ }^{2-}, \mathrm{Mg}^{2+}\right.$, and $\left.\mathrm{Ca}^{2+}\right)$ results in a modification of natural wettability characteristics. Thus, the Wettability Alteration (WA) to more 
water-wet conditions is a crucial parameter to decrease the residual oil saturation (Hirasaki et al., 2004; Saikia et al., 2018; Seethepalli et al., 2004; Webb et al., 2004). Zaheri et al. (2020) perform coreflooding analysis with carbonates using LSWI. They observed a relation between higher calcium content in formation water and a more oil-wet condition. They also noted the calcium concentration reduction and the sulfate presence affected the ultimate oil recovery.

According to Adegbite et al. (2017), wettability alteration is the main reason for incremental oil recovery by LSWI in carbonate reservoirs. Also, they suggest a new tendency to adapt the original ionic composition with a higher salinity range for each application. Through this concept, an update in the LSWI was generated, called Engineered Water Injection (EWI). Following the same hypothesis of the predecessor method, the differences are in raising the salinity limits, enabling to use higher ions concentrations.

Regarding the EWI method, a number of researches use an experimental approach to replicate the flow conditions in the reservoir and to determine the fundamental mechanism present in the analysis. Several works classify the effect of wettability alteration, fines migration, Multi-component Ionic Exchange (MIE), pH modification, effect salt-in, contact angle measurement, electrical double layer and interfacial tension as the main effects (Bidhendi et al., 2018; Dang et al., 2016; Ghosh et al., 2016; Jerauld et al., 2006; Xiao et al., 2018). According to different authors, it is possible to represent wettability alteration through changes in the relative permeability curves (Fathi et al., 2011; Reginato et al., 2019; Yousef et al., 2011). Wettability alteration is extensively investigated to understand the influence in the oil and water behavior, being directly relevant to the macroscopic relative permeability (Zhang et al., 2020).

The combination of these main mechanisms in EWI has a complex numerical background, making rare the development of analytical models capable of depicting this injection scheme. Therefore, it was common to use a simple relationship as a linear function among salinity, relative permeability, and capillary pressure (Dang et al., 2013). To enhance this modeling, researchers of the Computer Modelling Group $(C M G)$, the University of Calgary and University of Texas at Austin developed a new complete approach that translated some present mechanisms of LS injection, using some experimental results as input data to perform the simulations (Dang et al., 2016). The authors sought to couple some equations from exclusively geochemical software to a compositional flow simulator. Even knowing the numerical limitations, the authors proposed to validate this coupling by comparing the results of experimental injections in a coreflooding system (Fjelde et al., 2012). This test obtained quite significant results in this coupling to the flow simulator. Another aspect of the existing models for LSW/EWI simulation is a simplistic assumption whose change in wettability implies only in the modification of two-phase flow parameters (Bourbiaux, 2020).

In most cases, the specific parameters required by simulation software to model the EWI are unknown, which makes this analytical tool useless without an initial experimental analysis. Thus, to provide an alternative to model this advanced injection with the absence of a laboratory data source, our study performs the training of a machine learning tool called Neural Net Fitting (NNF) that can reliably predict wettability changes considering a given salinity combination and relative permeability set in numerical simulation scale.

Moreover, we carry out an NPV maximization in a case study benchmark called UNISIM-II (Correia et al., 2015). The ionic concentration of water injected is optimized by the Fast Genetic Algorithm (FGA), which provides the economic analysis of EWI and common water injection.

\section{Methodology}

As this work was performed only in a computational environment, it was necessary to use synthetic information to compose the database for future neural network training; therefore, some templates provided by $C M G^{\circledR}$ were selected. We simulated these templates using EWI geochemical modeling with different salinity for each case through conventional software (compositional simulator). After that, a specific algorithm (Kr-Module) adjusted the initial relative permeability curves of a regular template until obtaining the same production simulation with geochemical modeling. The database generated was composed of the original $\mathrm{Kr}$ and corresponding salinity case as input and the newfound $\mathrm{Kr}$ curve as output, starting the network development. At the training stage, we tested different network patterns up to the maximum forecasting quality, based on statistical tools. The network provided a new $\mathrm{Kr}$ curve through the original curve and a given salinity. Then, we coupled the best neural network to the simulation, performing the validation by comparing the production outcome between the geochemical simulation (modeled in the $C M G$ software) and the ANN.

Finally, ensuring the reliable application of the neural network, we coupled it to the optimization phase with the Fast Genetic Algorithm (FGA) to maximize the profits considering a range of costs, concluding the workflow (Fig. 1).

\subsection{Conventional EWI modeling and simulation}

Both modeling ways (geochemical EWI and coupled by ANN) use the $C M G$ software for simulation. The software requires informing the initial geochemical conditions of the EWI, such as the modeling method, the formation water salinity, the geochemical reactions considered and rock mineralogy. All the simulated cases keep the same input parameters, assigning the injection salinity as the only change agent in the production outcome.

\subsection{Database for neural network training}

The database consists of 19 synthetic reservoir models selected from the $C M G$ collection, from which the similarity with carbonate petrophysics and the possibility to apply the EWI modeling were the criteria to choose on these templates. Some of these are based on the SPE comparative solution project, which are generic benchmarks developed 


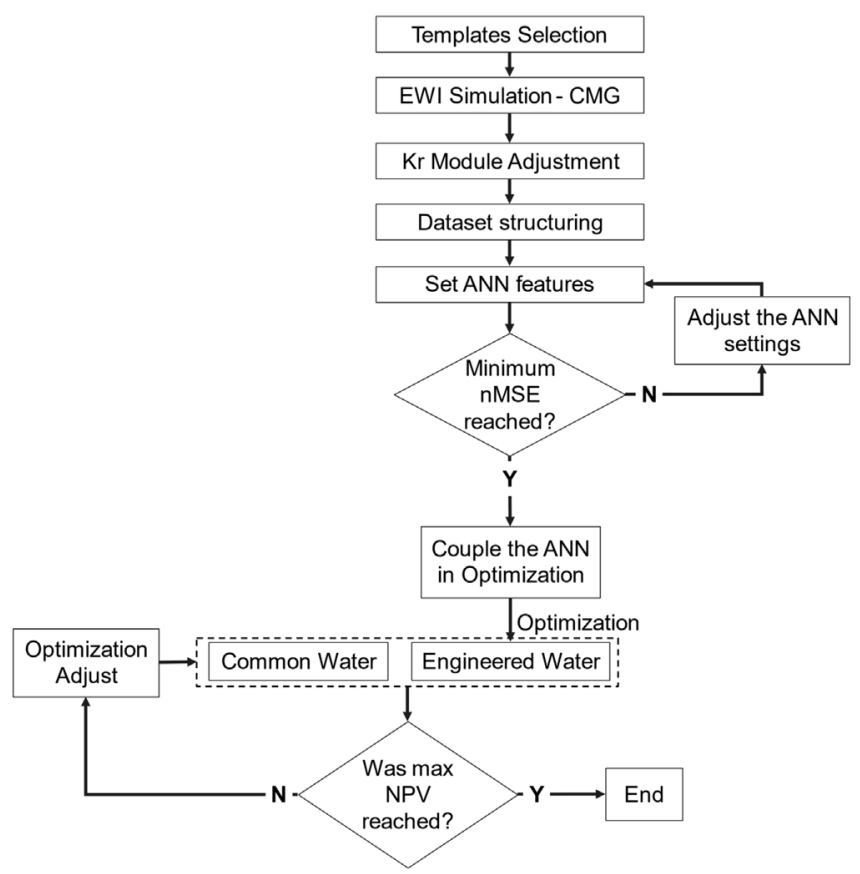

Fig. 1. Workflow of the general methodology.

through experimental data and used to compare simulation performance or practice the functions of the software. Their particularities were also maintained, such as the wells position, flow rates, grid size, oil composition, and others, for a better network generalization, so that the results used in training were comprehensive in the reservoir configuration. Each template received the EWI modeling 15 times with random salinity, totalizing 285 cases. We defined the database structure with original $\mathrm{Kr}$ curves, their corresponding salinity, and the new Kr curve produced from conventional EWI. However, the commercial software becomes limited in the initial $\mathrm{Kr}$ curves and does not provide the state of the curve after the simulation. Thus, to generate this information, we developed the algorithm called Relative Permeability Module. This code aims to minimize the error between productions of the same template with and without EWI modeling, assigning adjustments to the $\mathrm{Kr}$ model curve without EWI to reduce this error (Fig. 2). In practice, the Kr-Module adjusts the relative permeability of the model until the production result with the altered $\mathrm{Kr}$ curve be equal to the EWI. Thus, the new Kr correlates with the production change simulated by the EWI method and its salinity used.

This module was coupled with the Fast Genetic Algorithm (Sampaio et al., 2015) but adapted to minimize the error between the expected and simulated production outcomes, as shown in Figure 3. The algorithm inspiration is the evolution of a population through the generations (as in natural selection) using crossover and mutation until achieving the best solution (elite individual); in this case, it is the result with a minimum of the normalized Mean Squared Error (nMSE). Thus, the code requires the number of generations and quantities of individuals for generations to run. This code presents improvements in its solution speed, working with advanced modules and enhancing the simple crossover, parent selection, and evaluation function types.

Recursively, the algorithm performed the adjustments to each specified model, saving its results in the database. We also converted the Kr curve into Corey equation parameters (Eqs. (1) and (2)), establishing as input the original Kr-Corey parameters, their corresponding potential ion concentration and output the changed Kr-Corey parameters (Fig. 4). This Kr curve transformation was necessary following the network-training criteria to reduce repeated data. The dataset parameters were selected to achieve the best of the neural network training. Therefore, the initial conditions (Swc and Kro at Swc) of multiple reservoir types were included in order to contribute to the improvement in the ANN performance.

Thus, the number of input parameters was equal to 12 with 8 for the Corey equation, 3 to salinity concentration, and 1 to salt interpolator. The output corresponded to 8 from the Corey equation. Brooks and Corey (1964) developed the equations below to allow calculating the permeability of a fluid at a given saturation that the medium is at the reference fluid:

$$
\operatorname{kro}=\operatorname{krocw}\left(\frac{1-\mathrm{Sw}-\mathrm{Sor}}{1-\mathrm{Scw}-\mathrm{Sor}}\right)^{\mathrm{no}},
$$

$$
\mathrm{krw}=\operatorname{krwor}\left(\frac{\mathrm{Sw}-\mathrm{Swcrit}}{1-\text { Swcrit }- \text { Sor }}\right)^{\mathrm{nw}}
$$

where equation (1) is for oil relative permeability and equation (2) for water relative permeability of Corey formulation.

The parameters used in the network training are:

- Krocw - Relative permeability of oil with connate water condition;

- Krwor - Relative permeability of water in oil residual condition;

- $\mathrm{Sw}$ - Water saturation;

- Sor - Residual oil saturation;

- Scw - Connate water saturation;

- Swcrit - Critical water saturation;

- No - Corey exponent of oil;

- $\mathrm{Nw}$ - Corey exponent of water.

\subsection{Neural net fitting features}

The best ANN following the MATLAB ${ }^{\circledR}$ applications for prediction purposes was the Neural Net Fitting (NNF) that can solve the data fitting problem using a simple architecture named feedforward. Mohaghegh (2000) defined the feedforward network as a set of neurons grouped in layers, where they usually consist of an input layer, hidden layer and output layer, as shown in Figure 5. The number of input neurons is equal to the number of parameters presented to the network; this also happens in the output layer, and the hidden layer can vary in neurons or layers. This interconnected system and composed of neurons works in three 


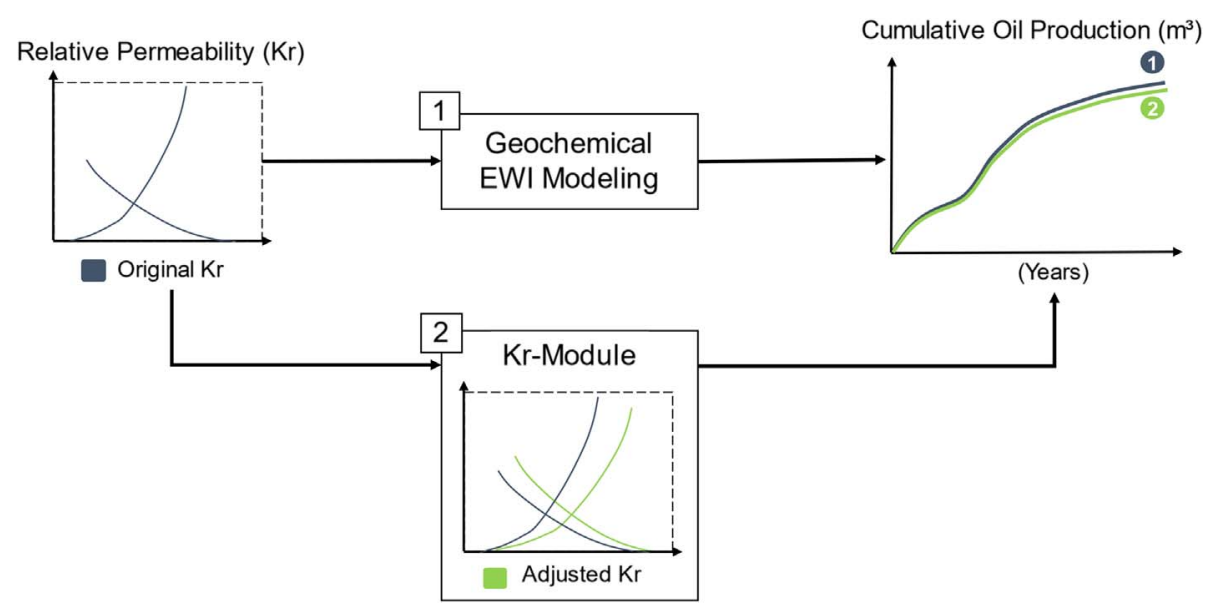

Fig. 2. Relative Permeability Module procedure.

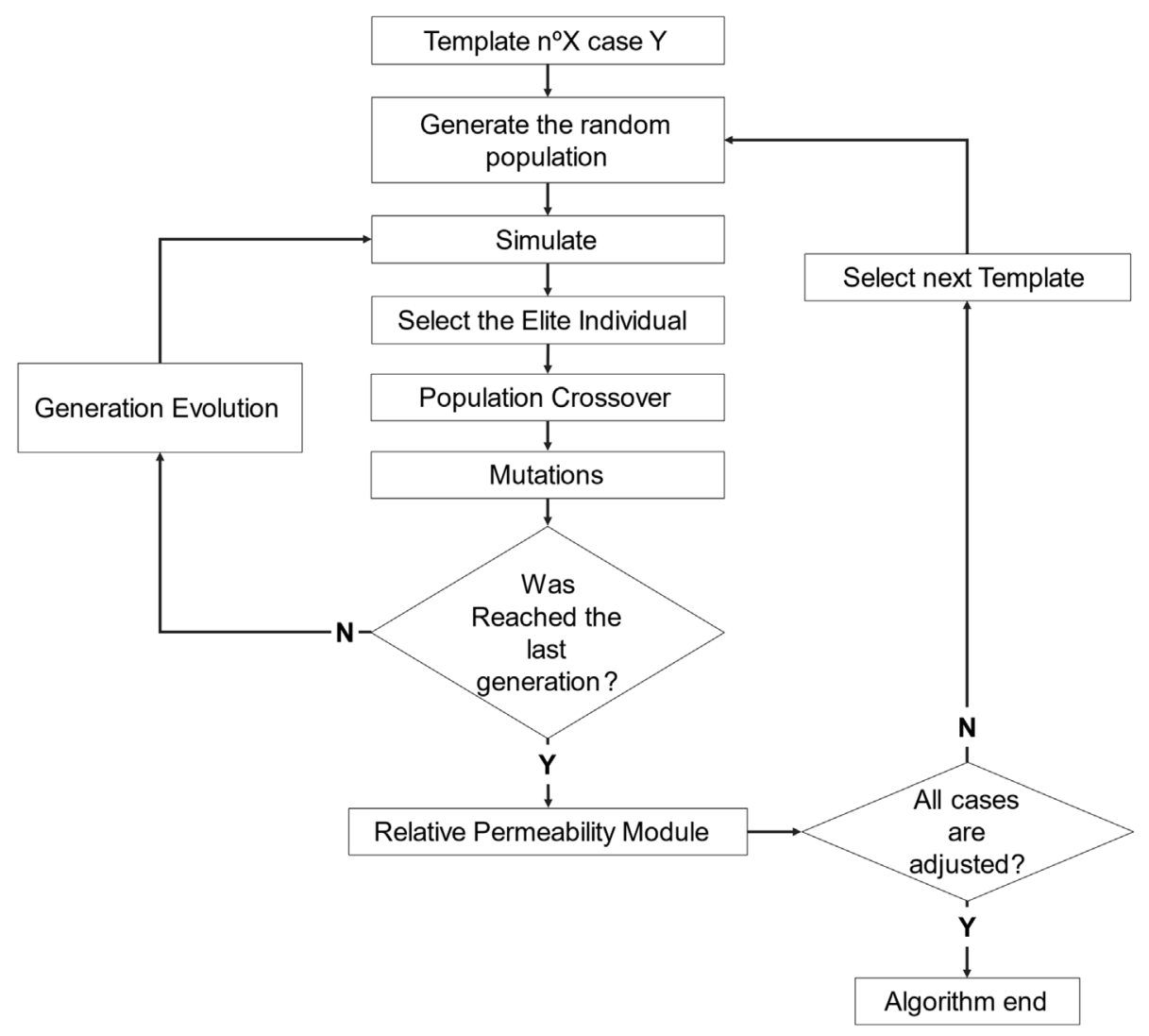

Fig. 3. Workflow of Relative Permeability Module coupled to FGA algorithm.

main steps: multiplication, sum and activation. The neuron multiplies each input data with its respective weight, sums these results, and uses a filter called the Activation Function (Strik et al., 2005).

This ANN uses a supervised learning method, which generally performs its training process combining the input data with the output (or labels), facilitating the creation of regression or classification, and indicating a quantitative relationship between them. Yet the limitation is that the training database needs to be complete, without missing data (Ghahramani, 2004; Rajasekaran and Pai, 2017; Shobha and Rangaswamy, 2018; Talabis et al., 2015).

Another important aspect of configuring the network is its training algorithm, for which we opted for the Bayesian Regularization (BR). We performed some training tests with the other methods available, but both these results and theoretical concepts of the BR method converged to its use. This method is a mathematical process to adapt a 


\begin{tabular}{ccccccccc|ccccc} 
& \multicolumn{7}{c|}{ Input Parameters } & \multicolumn{5}{c}{ Output Parameters } \\
\cline { 2 - 14 } & No & $\mathrm{Nw}$ & Sorw & $\mathrm{Scw}$ & $\ldots$ & $\mathrm{SO}_{4}{ }^{2-}$ & $\mathrm{Mg}^{2+}$ & $\mathrm{Ca}^{2+}$ & $\mathrm{No}$ & $\mathrm{Nw}$ & Sorw & $\mathrm{Scw}$ & $\ldots$ \\
\cline { 2 - 14 } Tpl-1 EW1 & 3.4 & 2.3 & 0.7 & 0.2 & $\ldots$ & 9783 & 8744 & 2376 & 3.2 & 2.0 & 0.6 & 0.3 & $\ldots$ \\
\hline Tpl-1 EW2 & 2.5 & 4.3 & 0.5 & 0.1 & $\ldots$ & 3265 & 6431 & 3489 & 1.3 & 3.5 & 0.8 & 0.1 & $\ldots$ \\
\hline$\ldots$ & $\ldots$ & $\ldots$ & $\ldots$ & $\ldots$ & $\ldots$ & $\ldots$ & $\ldots$ & $\ldots$ & $\ldots$ & $\ldots$ & $\ldots$ & $\ldots$ & $\ldots$ \\
\hline Tpl-1 EWn & 3.1 & 3.7 & 0.9 & 0.17 & $\ldots$ & 4354 & 9822 & 3245 & 2.5 & 3.1 & 0.7 & 0.2 & $\ldots$ \\
\hline
\end{tabular}

Fig. 4. Illustrative structure of the database for ANN training separated into input and output data.

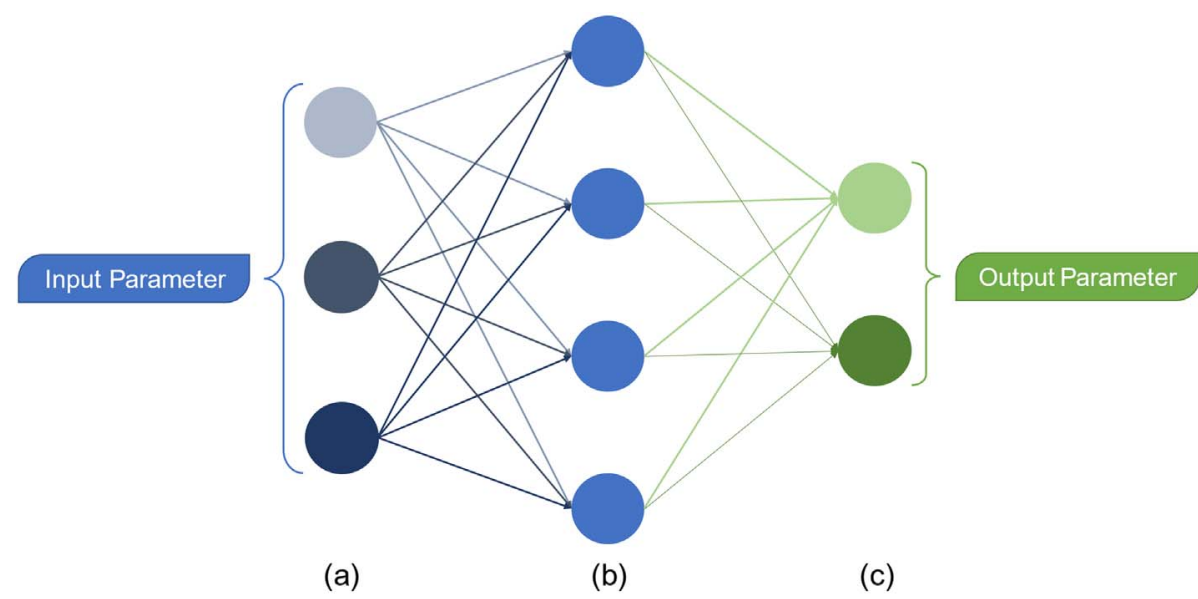

Fig. 5. Architecture of feedforward network, (a) input layer; (b) hidden layer, and (c) output layer.

nonlinear regression to statistical problems (well-posed). The robustness of the model minimizes the effect of overtraining or overfitting and has an Automatic Relevance Determination (ARD). The ARD calculates the relevance for each input parameter, neglecting the irrelevant or highly correlated indexes (Burden and Winkler, 2008). The Bayesian Regularized ANN (BRANNs) incorporates probabilistic interpretation into the regularization scheme. The regularization is a method to penalize the highest and the smallest weight in the neuron network and to ensure the best generalization (Kayri, 2016). According to the $M A T L A B^{\circledR}$ guide, this BRANNs algorithm is slower in learning because at each learning epoch, the algorithm performs the relevance analysis, reducing the training speed but conserves the quality of the forecast, being ideal in training cases with a low number of samples, a high number of variables and non-linearity.

We also carried out another training test looking for the number of neurons in the hidden layer that would guarantee the maximum forecasting quality. We tested five different configurations (12,15,17,20, and 25), and the results with 15 neurons in the hidden layer showed the best performance. All training followed a cross-validation process with the same configuration (70\% of the data for training, $15 \%$ for validation and $15 \%$ for testing); 30 samples of the UNISIM-II case study (Correia et al., 2015) were generated to serve as a second validation of each network test, using the error between the expected and predicted result as a quality analysis. Thus, the best network was called "Net15 BR".

\subsection{FGA and NNF coupling}

To assess the economic attractiveness of EWI, we carried out a process of production optimization aiming at maximizing the NPV. We conducted a first optimization of the operational variables of the wells (injection/production flow rate and pressure) with common water injection, considering the economic scenario of the benchmark used. Next, we performed the optimization of the same model, using EWI; in this case, variables of wells, the ion concentrations, and the interpolator were added as optimization parameters. Thus, it was possible to compare which injection method would yield the highest profit and what the optimized ion configuration would be.

As a tool for optimization, the original Fast Genetic Algorithm (Sampaio et al., 2015) was used, applied in this stage to maximize the NPV field. The best-trained network was coupled to the optimization, adding a step to the FGA code with the salinity concentration and interpolator ion as decision variables. This routine also extracted the original $\mathrm{Kr}$ curve from the corresponding model optimized, transforming it into Corey parameters and organizing with the chosen salinities, giving these data to the neural network 
Table 1. Parameters for modeling EWI in the simulator.

\begin{tabular}{lllll}
\hline \multicolumn{4}{c}{ EWI parameters for simulator } \\
\hline $\begin{array}{l}\text { Kr interpolation } \\
\text { begin }(\mathrm{ppm})\end{array}$ & $\begin{array}{c}\text { Kr interpolation } \\
\text { end }(\mathrm{ppm})\end{array}$ & $\begin{array}{l}\text { Sets of } \\
\text { inputs }\end{array}$ & $\begin{array}{c}\text { Sor reduction } \\
(\text { Sor-EW } / \text { Sorw })\end{array}$ & $\begin{array}{c}\text { Krw reduction } \\
(\text { Kr-EW } / \text { Krw })\end{array}$ \\
\hline 700 & 200 & 2 & 0.6 & 0.75 \\
\hline
\end{tabular}

Table 2. Ionic concentration of water injection and mineral percentual range.

\begin{tabular}{|c|c|c|c|c|c|c|c|c|}
\hline \multicolumn{7}{|c|}{$\begin{array}{c}\text { Formation water } \\
\text { salinity (ppm) }\end{array}$} & \multicolumn{2}{|c|}{$\begin{array}{l}\text { Formation mineral } \\
\text { concentration }\end{array}$} \\
\hline $\mathrm{pH}$ & $\mathrm{Cl}^{-}$ & $\mathrm{SO}_{4}{ }^{2-}$ & $\mathrm{Ca}^{2+}$ & $\mathrm{Mg}^{2+}$ & $\mathrm{HCO}^{3-}$ & $\mathrm{Na}^{+}$ & Calcite & Dolomite \\
\hline 7 & 17500 & 100 & 100 & 100 & 100 & 17500 & 0.5 & 0.5 \\
\hline
\end{tabular}

"Net15_BR", which provided the new Kr curve. In general, this coupling was necessary to predict the new $\mathrm{Kr}$ curve at a given ionic concentration defined by the optimization process, inserting this curve in the corresponding model before the simulation stage.

\section{Case studies}

\subsection{Engineered water conventional simulation features}

As previously mentioned, it is necessary to preset of the salinity composition of the formation water, mineralogic content, the geochemical reactions, and the modeling method to perform the simulation with EWI. Thus, to simplify the modeling method, we select the interpolator ion method and its salinity range (Tabs. 1 and 2).

These settings were defined arbitrarily, as the formation water composition had about 35000 ppm of total salinity, composed basically of $\mathrm{Na}^{+}$and $\mathrm{Cl}^{-}$. For mineral concentrations, we set $50 \%$ dolomite and calcite, according to the pattern found in most carbonates.

Each template selected for constructing the database generated 15 new cases of EWI geochemical modeling, with random salinity ranging from 1000 to 9999 ppm and considering the same configurations on the formation water and mineralogical content shown above (Tabs. 1 and 2). In every five cases with EWI, the alteration in the potential interpolation ion (between $\mathrm{SO}_{4}{ }^{2-}, \mathrm{Mg}^{2+}$, and $\mathrm{Ca}^{2+}$ ) was defined, increasing the diversity of ionic combinations and their corresponding effects. Finally, with all the 19 templates with 15 EWI random salinity cases created, we simulated these 285 samples and extracted the required data for the next step in the training network. With the data in Tables 1 and 2 kept the same for all tested models, changes in production are attributed exclusively to different ionic combinations. That allows the correlation between the new $\mathrm{Kr}$ data via $\mathrm{Kr}-\mathrm{Module}$ with the corresponding salinity used in each model.

The fluid model was composed of seven components $\left(\mathrm{Cl}^{-}, \mathrm{SO}_{4}{ }^{2-}, \mathrm{Ca}^{2+}, \mathrm{Mg}^{2+}, \mathrm{HCO}^{3-}, \mathrm{Na}^{+}, \mathrm{H}^{+}\right)$, and rock contained two minerals (Calcite and Dolomite). Four aqueous phase reactions to describe the ionic interactions in the geochemical simulation were included:

$$
\begin{gathered}
\left(\mathrm{HSO}_{4}^{-}\right) \leftrightarrow\left(\mathrm{H}^{+}\right)+\left(\mathrm{SO}_{4}^{2-}\right), \\
\left(\mathrm{CaCl}^{+}\right) \leftrightarrow\left(\mathrm{Ca}^{2+}\right)+\left(\mathrm{Cl}^{-}\right), \\
\left(\mathrm{MgCl}^{+}\right) \leftrightarrow\left(\mathrm{Cl}^{-}\right)+\left(\mathrm{Mg}^{2+}\right), \\
\left(\mathrm{NaSO}_{4}^{-}\right) \leftrightarrow\left(\mathrm{Na}^{+}\right)+\left(\mathrm{SO}_{4}{ }^{2-}\right),
\end{gathered}
$$

These reactions were selected, respecting the main interactions between the $\mathrm{NaCl}$ and the three potential ions. The mineral phase reactions that incorporate the Calcite and Dolomite dissolution and precipitation are shown below:

$$
\begin{aligned}
\left(\mathrm{CaCO}_{3}\right)+\left(\mathrm{H}^{+}\right) \leftrightarrow & \left(\mathrm{Ca}^{2+}\right)+\left(\mathrm{HCO}_{3}\right) \\
\left(\mathrm{CaMg}\left(\mathrm{CO}_{3}\right)_{2}\right)+2\left(\mathrm{H}^{+}\right) \leftrightarrow & \left(\mathrm{Ca}^{2+}\right)+2\left(\mathrm{HCO}_{3}^{-}\right) \\
& +\left(\mathrm{Mg}^{2+}\right) .
\end{aligned}
$$

According to Dang et al. (2015), the difference between the composition of the in-situ and injected water disrupts the initial geochemical conditions, so the chemical equilibrium reactions calculate the behavior of these salts in each reservoir cell. On the other hand, the wettability alteration modeling occurs through shifting in the relative permeability curves, and the controller of this adjustment in the curves is the ion compositions obtained through these equilibrium reactions. Thus, this ionic balance in each cell allows a more precise adjustment in the relative permeability curves, considering the variation in salinity in different regions of the model.

\subsection{Optimization settings}

At the optimization stage, a decision criterion was necessary for the algorithm to select an interpolator ion as an adjustable variable defining a chosen range of between 1 and 3 , and the algorithm was specified as shown in Table 3. 
Table 3. Range defined for the algorithm chosen between each interpolator ion.

\begin{tabular}{ll}
\hline \multicolumn{2}{c}{ Definition of Ion Interpolator } \\
\hline $\mathrm{SO}_{4}{ }^{2-}$ & Between 1 and 1.5 \\
$\mathrm{Ca}^{2+}$ & Between 1.6 and 2.5 \\
$\mathrm{Mg}^{+}$ & Between 2.6 and 3 \\
\hline
\end{tabular}

The algorithm thus selected the value within the range, and automatically transformed that number into the equivalent potential ion.

After the successful coupling of the neural network to the FGA, the initial parameters of the optimizations were configured (Tab. 4). We performed a series of tests, setting the maximum number of 200 individuals in the optimizations.

\subsection{UNISIM-II benchmark}

The case study selected in this work was the UNISIM-II, developed by the Unisim group from Unicamp (Correia et al., 2015). The model structure combines the Brazilian Pre-salt and Ghawar fields, providing the description of an economic scenario as well. The dimension of this carbonate reservoir model is $5000 \times 5000 \times 150 \mathrm{~m}$ and composed of 16 faults. Each grid cell has $50 \times 50 \times 1 \mathrm{~m}$, with a thin super-k zone. Further field information is:

- Depth of reservoir between 5000 and $5500 \mathrm{~m}$ from the sea level

- Initial reservoir pressure $560 \mathrm{kgf} / \mathrm{cm}^{2}$

- Intermediate-wet relative permeability

- Live oil viscosity to $1.14 \mathrm{cP}$

- Reservoir temperature equal to $58.8^{\circ} \mathrm{C}$.

The benchmark determines operational boundaries for injection and production wells (Tab. 5), used as upper and lower limits in the well optimization step.

To minimize the simulation time, we reduced the reservoir size selecting a section with $6 \times 6 \times 30$ cells (Fig. 6 ) chosen in a representative location, that preserves its architecture and behaviors. We also implemented one vertical injection well with a quarter of the area open to flow in the corner of this cut model, and a production well with the same condition in the opposite corner. The layout of the wells follows the injection pattern with a quarter of five-spot configuration, with a $450 \mathrm{~m}$ distance between them.

The deterministic approach of the benchmark used contains its economic scenario (Tab. 6), which updated the gas cost and price based on the US natural gas price. Following the indications in the model description, we calculated the investment cost in the platform using the below equation presented by Hayashi (2006) (see Eq. (9)). We considered the maximum wells capacities of a quarter of the given description, adjusting this investment to the settings defined for the cut model.
Table 4. Parameters for optimization with FGA.

Fast genetic algorithm parameters

Number of generations 20

Population size 10

Elite individuals $\quad 1$

Crossover rate 0.8

Table 5. Operational well conditions, adapted by Correia et al., (2015).

\begin{tabular}{lcc}
\hline Type & $\begin{array}{c}\text { Vertical } \\
\text { producer }\end{array}$ & $\begin{array}{c}\text { Vertical } \\
\text { injection }\end{array}$ \\
\hline $\begin{array}{l}\text { Max. water rate } \\
\left(\mathrm{m}^{3} / \text { day }\right)\end{array}$ & - & 5000 \\
$\begin{array}{l}\text { Min. oil rate }\left(\mathrm{m}^{3} / \text { day }\right) \\
\begin{array}{l}\text { Max. liquid rate } \\
\left(\mathrm{m}^{3} / \text { day }\right)\end{array}\end{array}$ & 20 & - \\
$\mathrm{BHP}\left(\mathrm{kgf} / \mathrm{cm}^{2}\right)$ & 2000 & - \\
\hline
\end{tabular}

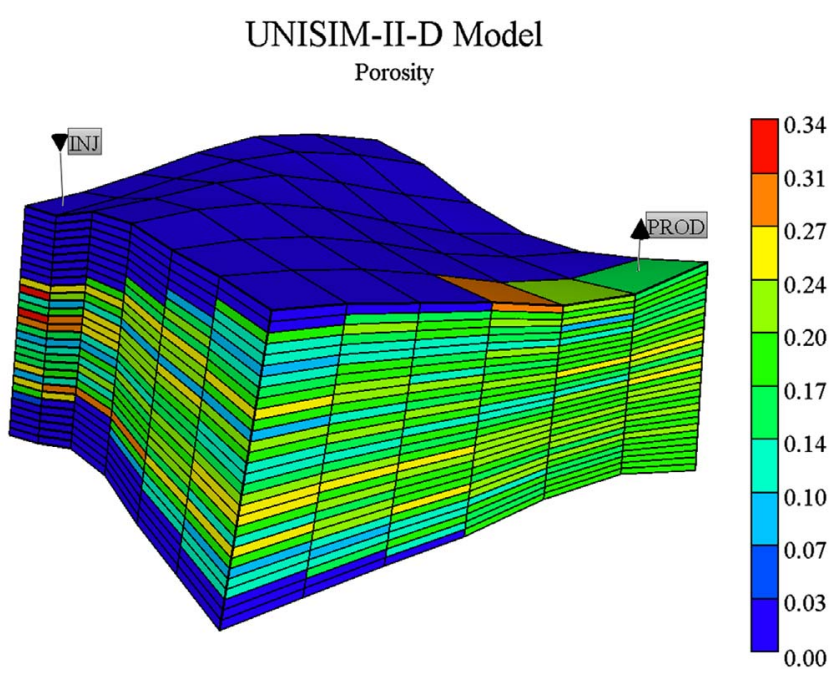

Fig. 6. Cut model from UNISIM-II-D, showing the porosity parameter.

$$
\begin{aligned}
\mathrm{INV}_{\text {PLAT }} & =417+\left(13.2 \times C p_{\mathrm{o}}+3.2\right. \\
& \left.\times C p_{1}+3.2 \times C p_{\mathrm{w}}+3.2 C i_{\mathrm{w}}+0.1 \times n_{\mathrm{w}}\right) .
\end{aligned}
$$

Given that:

- INV $\mathrm{ILAT}_{\text {PLA }}$ Investment on the platform (USD millions)

- $C p_{\mathrm{o}}$ : Oil processing capacity $\left(1000 \mathrm{~m}^{3} /\right.$ day $)$

- $C p_{1}$ : Liquid processing capacity $\left(1000 \mathrm{~m}^{3} /\right.$ day $)$

- $C p_{\mathrm{w}}$ : Water processing capacity $\left(1000 \mathrm{~m}^{3} /\right.$ day $)$

- $C i_{\mathrm{w}}$ : Water injection capacity $\left(1000 \mathrm{~m}^{3} /\right.$ day $)$

- $n_{\mathrm{w}}$ : Well's number. 
Table 6. Economic scenario used in the optimization study.

\begin{tabular}{|c|c|c|}
\hline Variables & & Values \\
\hline Oil price & & $54.76 \mathrm{US} \$ / \mathrm{STB}$ \\
\hline Gas price & & $0.70 \mathrm{US} \$ / \mathrm{STB}$ \\
\hline \multicolumn{3}{|c|}{ Costs (US\$/stb) } \\
\hline Oil production & & 10.952 \\
\hline Gas production & & 0.4675 \\
\hline Water production & & 1.1 \\
\hline Engineered water injection & & 1.98 \\
\hline Water injection & & 1.1 \\
\hline \multicolumn{3}{|c|}{ Investments (US\$ millions) } \\
\hline Drilling and completion vert. well & & $22.8 / \mathrm{m}$ \\
\hline Connection vertical well-platform & & 13.3 \\
\hline Platform & & Equation (9) \\
\hline \multicolumn{3}{|c|}{ Fiscal Tax (\%) } \\
\hline Royalties & & 10 \\
\hline Social taxes rate & & 9 \\
\hline Income tax & & 25 \\
\hline $\mathrm{PIS}^{1}$ & & 1.65 \\
\hline COFINS $^{1}$ & & 7.6 \\
\hline
\end{tabular}

${ }^{1}$ PIS and COFINS are specific Brazilian taxes.

\section{Results and discussion}

In this section, we divided the results into two parts. First, we approached the quality of neural network prediction based on statistical tools (nMSE). We then compared the optimization results, evaluating the final profit with the injection of seawater and EWI, the wells conditions, and the optimum salinity solution. We also optimized four cases of EWI varying only the cost of this engineered water injection, which showed its influence on the profits and on the optimized ion composition.

\subsection{Validation of network predictions}

We tested different neural network configurations to guarantee the best performance. We compared five sizes of hidden layers with two distinct training algorithms (Fig. 7). According to the theory, the training method of Bayesian Regularization (BR) is more indicated due to its data configuration, even so, we tested the training with the Levenberg-Marquardt (LM) algorithm to ensure that.

In Figure 7, the comparison uses the data generated specifically for validating the networks already trained with the 30 cases of random salinity from the UNISIM-II model. Note that these data are not used in the training of the neural network, proving its ability to predict and to generalize through the normalized Mean Squared Error (nMSE). The nMSE shows that the closer to zero, the more similar the forecast result is than the expected value. Thus, based on nMSE, the neural network that obtains the best result is the one with 15 neurons in the hidden layer (Net15_BR). We noted that the variation between the nMSE with each training algorithm is not sharp, but this difference generates divergence in the production simulation because the $\mathrm{Kr}$ has high sensitivity in the software, making it essential to use the network with the best performance.

It was possible to confirm the benefits of using the BR network with the determination of relevance (ARD) and robust regularization (Fig. 7). The absence of that in the LM algorithm impaired its training, which achieved high learning speed; but in these conditions, the regularization effort by BR is compensated with a better forecast.

The Net15_BR was coupled to the simulator to forecast $\mathrm{Kr}$ curves at a given salinity of the water injection, and we started to investigate the quality of this approach in production simulation. Thus, using the UNISIM-II model and its 30 test cases, we compared the production result between geochemical EWI modeling of GEM simulator and the ANN approach, following the same salinity compositions as the test models. The nMSE was applied to quantify the similarity in the oil and water production curves between these two schemes for EWI modeling (Fig. 8). The comparison of results shows a satisfactory quality in the replacement of the geochemical modeling $C M G$ package with the neural network, which was able to reproduce similar behaviors in the production simulation through only changes in Kr. The mean of the nMSE for the 30 cases compared in the analysis was mean-nMSE of oil equal to 0.0528 and mean-nMSE of water equal to 0.1189 , with satisfactory results of the simulation performance coupling the ANN, enabling its use at the optimization stage.

Figure 9 displays a plot referring to model 14, one of the cases with values closer to the average of the tested models. We plot with production histories generated between the 


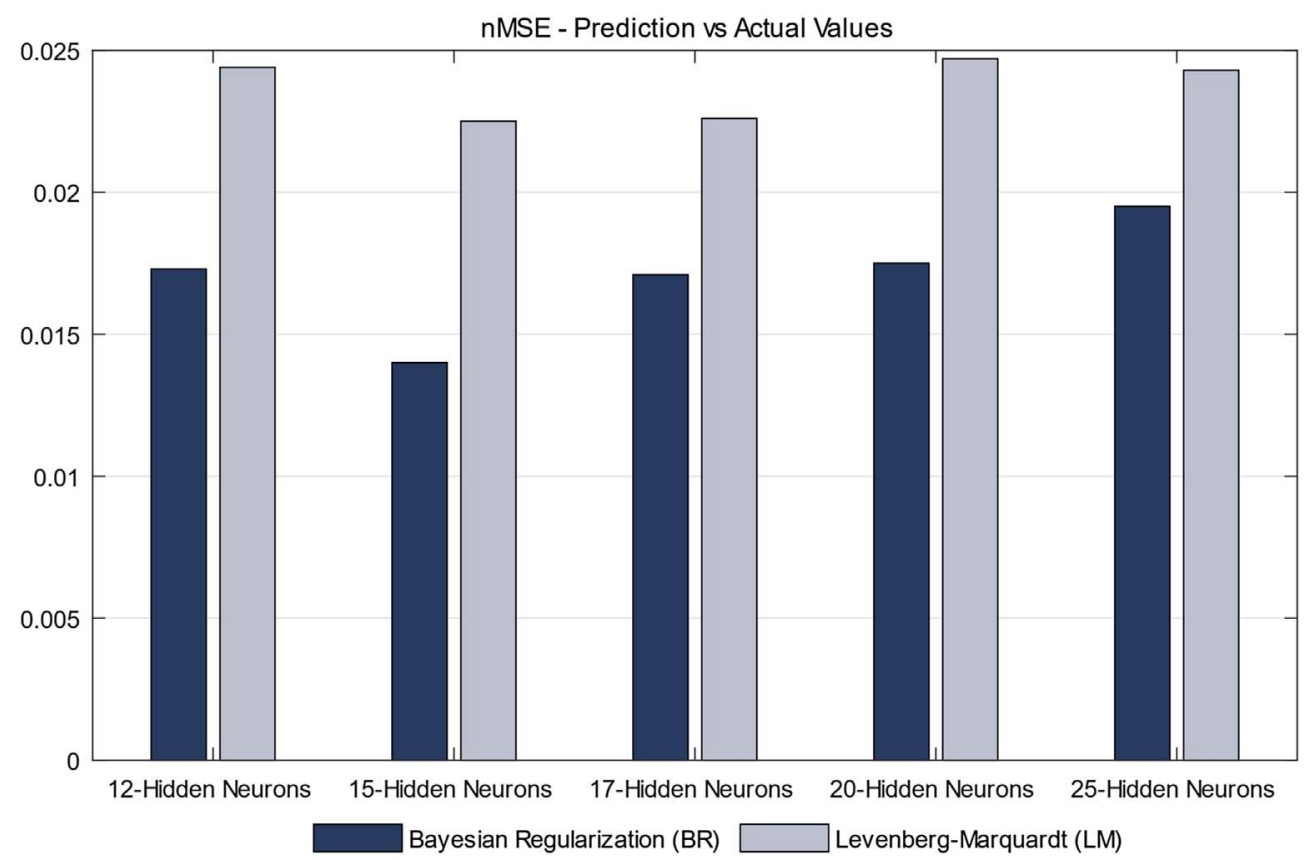

Fig. 7. Comparison with the prediction performance network varying the number of hidden neurons and learning algorithms.

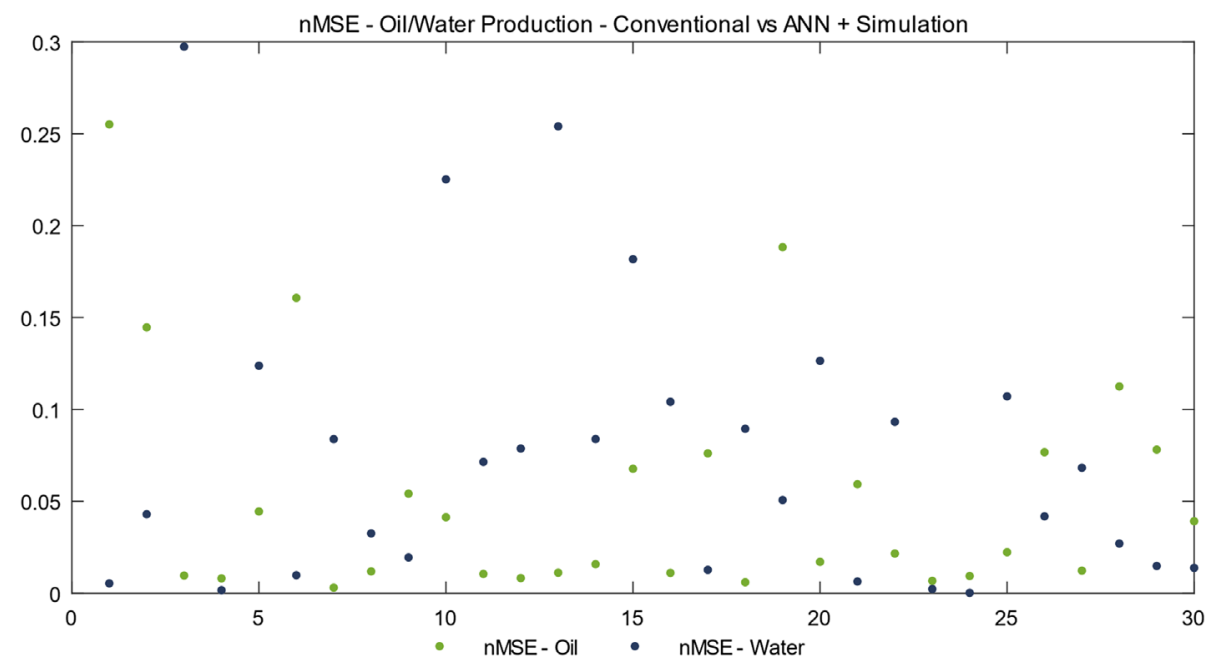

Fig. 8. Normalized Mean Squared Error (nMSE) of oil/water production between conventional simulation and simulation with Net15_BR coupled.

compared methods, being possible to observe the quality that the ANN approach (in green) reproduces.

We also compared the aspect of simulation time (Fig. 10), in which the ANN's predictive agility did not add more calculations to the numerical simulation, providing its simulation solution faster than conventional modeling. The software geochemical EWI modeling package adds calculation routines to predict the behavior of ion dissolution and adsorption rates, increasing the computational effort and the solution time. Therefore, the ANN application ensured similar results to the GEM modeling package with a significant time reduction.

\subsection{Optimization results}

The optimization of UNISIM-II using seawater injection and EWI was performed, enabling the comparison of performance in oil recovery and its effects on the financial return on each injection project. The results are based on real costs and prices, but do not represent legitimate profitability; even so, they still allow a reliable comparison.

The economic evaluation description of the benchmark did not contain the EWI cost, so we define an increase of $25 \%, 75 \%, 300 \%$, and $500 \%$ in relation to seawater injection cost. Thus, we performed four cases of EWI optimization, 


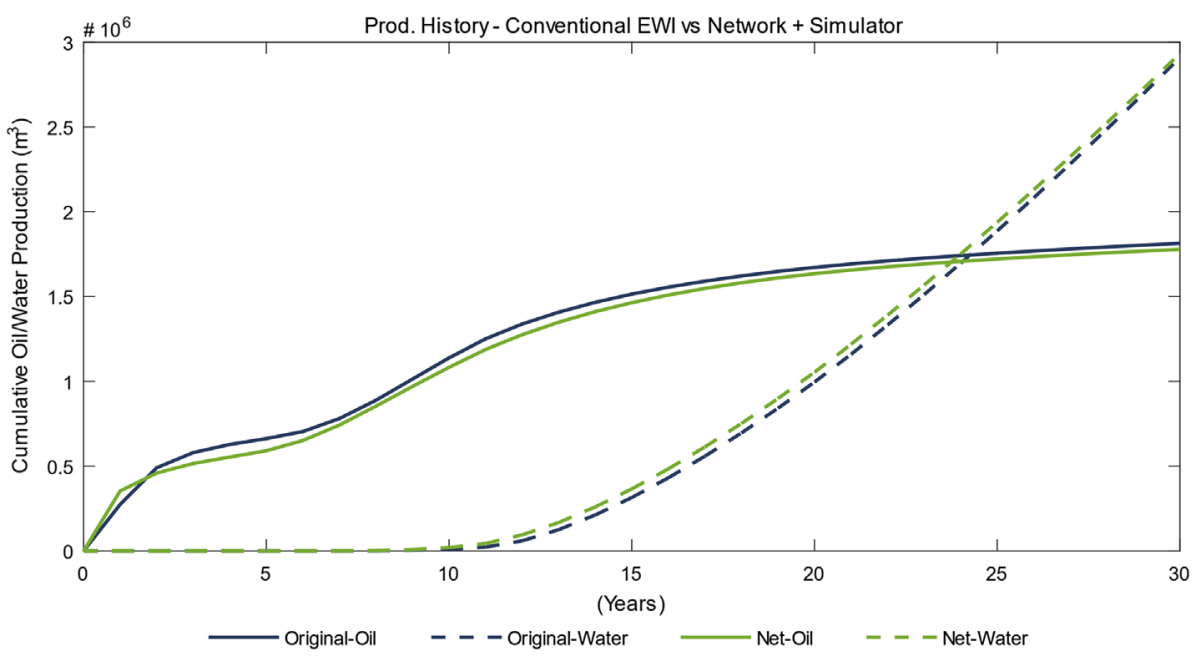

Fig. 9. Simulation results, comparing the traditional EW simulation and simulation with Net15_BR relative permeability results.

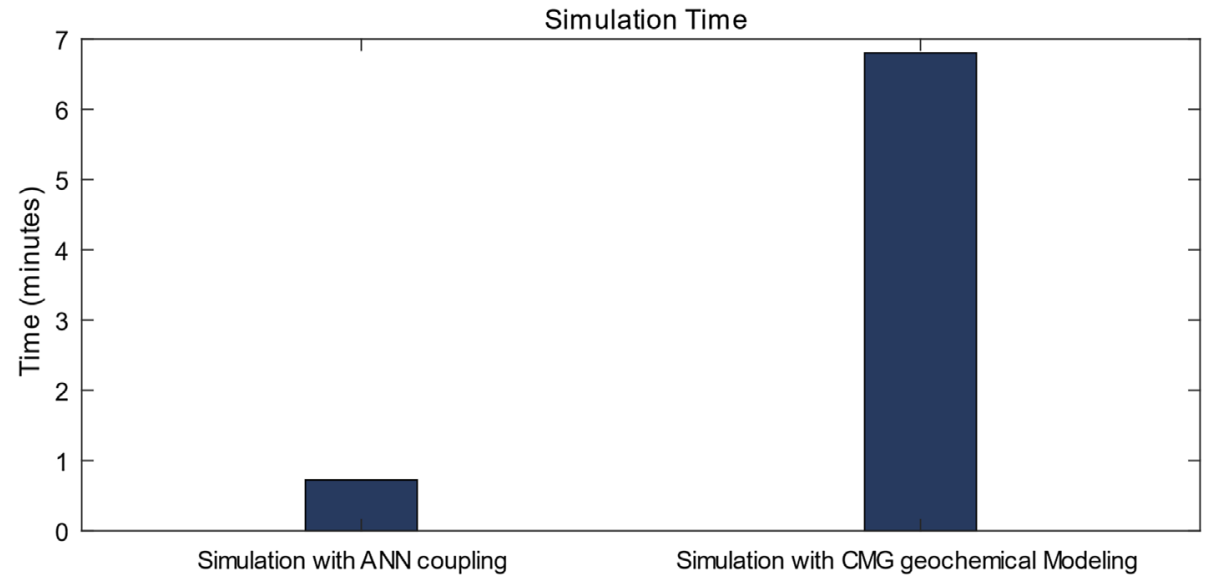

Fig. 10. Simulation time comparison between the ANN coupling solution and conventional geochemical modeling.

Table 7. Optimization results for each adjusted variable in the common water injection and engineered salinity.

\begin{tabular}{lcccccccccc}
\hline Case & $\begin{array}{c}\text { INJ-rate } \\
\mathrm{m}^{3} / \text { day }\end{array}$ & $\begin{array}{c}\text { INJ-press } \\
\mathrm{kPa}\end{array}$ & $\begin{array}{c}\text { PRD-rate } \\
\mathrm{m}^{3} / \text { day }\end{array}$ & $\begin{array}{c}\text { PRD-press } \\
\mathrm{kPa}\end{array}$ & $\begin{array}{c}\mathrm{Ca}^{2+} \\
(\mathrm{ppm})\end{array}$ & $\begin{array}{c}\mathrm{SO}_{4}{ }^{2-} \\
(\mathrm{ppm})\end{array}$ & $\begin{array}{c}\mathrm{Mg}^{2+} \\
(\mathrm{ppm})\end{array}$ & $\begin{array}{c}\text { EW-mod } \\
\text { NPV }\end{array}$ & $\begin{array}{c}\Delta N P V \\
(\mathrm{MMUS} \$)\end{array}$ & $\begin{array}{c}\Delta \text { MUS } \$) \\
(\mathrm{MMU}\end{array}$ \\
\hline Water & 4988.29 & 33919.73 & 1996.66 & 17943.14 & - & - & - & - & $\$ 16.95$ & - \\
EW-25 & 4866.87 & 33087.09 & 1961.96 & 17353.35 & 7127.23 & 5420.62 & 1033.83 & 3 & $\$ 66.57$ & $\$ 49.62$ \\
EW-75 & 4940.44 & 33591.59 & 1982.98 & 17710.71 & 7333.23 & 6627.23 & 1975.58 & 3 & $\$ 58.54$ & $\$ 41.60$ \\
EW-300 & 4975.48 & 33831.83 & 1992.99 & 17880.88 & 8931.33 & 8038.64 & 739.54 & 3 & $\$ 24.69$ & $\$ 7.74$ \\
EW-500 & 4898.4 & 33303.3 & 1970.97 & 17506.51 & 8715.52 & 8401.6 & 1661.66 & 3 & $\$ 8.22$ & $-\$ 8.73$ \\
\hline
\end{tabular}

varying only the water injection price with salinity control, adding to the analysis the changes in ion composition generated by differences in its cost.

The results of the variables of wells, ionic concentration, the ion interpolator, and corresponding maximum NPV for each optimization case are displayed in Table 7. Notice the pressure of wells and flow conditions are similar in all the optimized cases, assigning the injection salinity in NPV changes. Also, three cases of EWI (25\%, $75 \%$ and $300 \%)$ had higher profits than the common water (seawater) injection, indicating that the advanced method is potentially more profitable considering a margin of up to $300 \%$ increase in the injection cost.

When compared the results of accumulated production/ injection fluids between the methods used (Tab. 8), the oil recovery increases by about $8.7 \%$ with EWI; the injected 
Table 8. Fluids production/Injection and oil recovery factor in the optimum cases.

\begin{tabular}{lcccc}
\hline Case & Oil produced $\left(10^{5} \mathrm{~m}^{3}\right)$ & Water produced $\left(10^{5} \mathrm{~m}^{3}\right)$ & Water injection $\left(10^{5} \mathrm{~m}^{3}\right)$ & Oil recovery factor $(\%)$ \\
\hline Water & 15.61 & 19.19 & 39.63 & 37.74 \\
EW-25 & 19.66 & 9.45 & 36.38 & 47.53 \\
EW-75 & 19.58 & 8.61 & 35.66 & 45.35 \\
EW-300 & 18.30 & 10.64 & 35.25 & 44.22 \\
EW-500 & 19.06 & 7.96 & 34.59 & 46.07
\end{tabular}

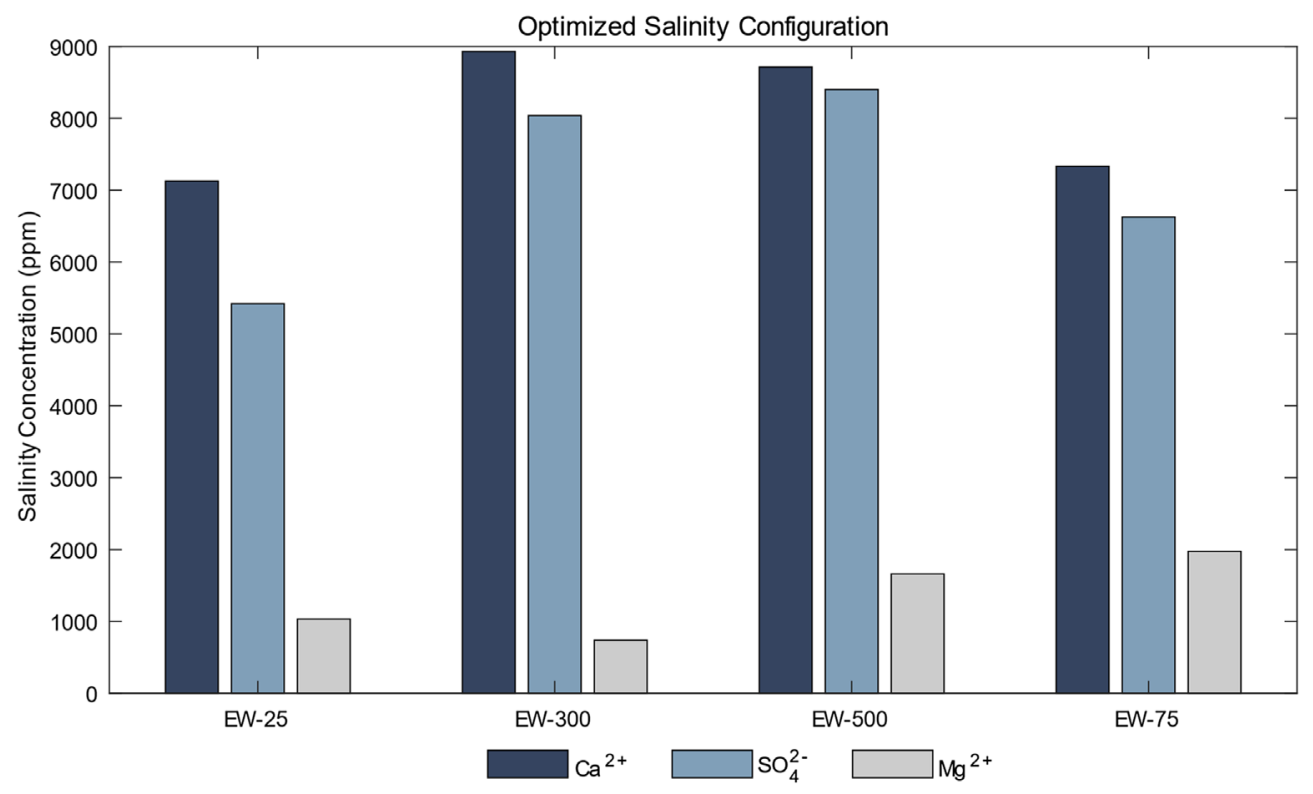

Fig. 11. Ionic concentration of water injection obtained by the optimization process.

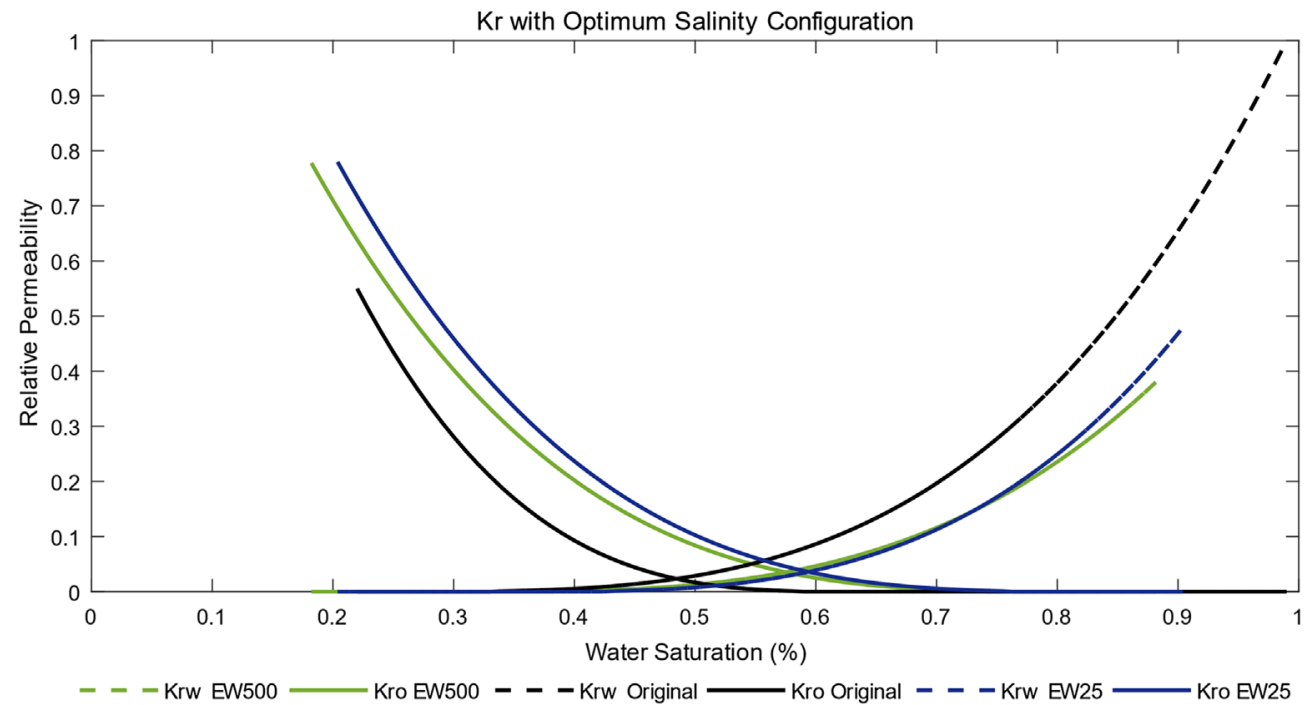

Fig. 12. Relative permeability of engineered water optimized versus normal relative permeability. 
volumes are maintained close, and the water production is reduced by around $52 \%$, saving this cost and improving the injection performance through ionic calibration. In sum, more oil was recovered with the same injection amount, and more water remained in the reservoir.

The optimized salinities (Fig. 11) show the sulfate and calcium with higher concentrations, increased their quantities with rising cost. All four EWI cases show $\mathrm{Ca}^{2+}$ as the interpolator ion (Tab. 7), but this does not minimize the effect of the other salts, which in this application changes with their different combinations, considering multiple influences between them.

This step shows the optimized concentrations are not low, reinforcing that to improve the projected water injection technology requires exploration with a higher range of ion concentrations considering their technical and economic viability. As pointed by Adegbite and Al-Shalabi (2020), the low salinity levels bring benefits in most injection cases. On the other hand, its optimization can converge to a more concentrated use of some ions, showing a greater versatility of the EWI technique.

Finally, we plot the relative permeability curves of the original case, EW-25, and EW-500 (Fig. 12), analyzing the changes that the ionic compositions produced. We observed an increase in the $\mathrm{Kr}$-Oil curve values and a reduction in Kr-Water with the proposed ionic concentrations when compared with the original case. The EWI has the potential to increase the difference between connate and critical water saturation due to changes in the oil flow. The Kr-Oil with EWI had lower saturation points of connate water than the original case, reinforcing this expected effect by the injection method. An increase occurs at the endpoint on the Kr-Oil curve with EWI, indicating a higher final water saturation, with a consequent reduction in residual oil saturation. Analyzing Figure 12 based on the changes in Sor and the shape of the Kr-Oil curve, we noticed an oil mobility modification by the optimized ionic injection, which resulted in a direct impact on the behavior of oil production and on the injection/production water. These comparisons indicate a change in the natural wettability of the rock preferential to water (more water-wet), corroborating the theories approached for the injection method.

\section{Conclusion}

In this article, we developed a feedforward neural network that performed changes in the relative permeability data given an ionic condition, having the potential to reproduce the same effects in the numerical simulation, considering the EWI geochemical modeling of the $C M G$ software. The development of ANN underwent practical tests to define its configurations, such as the number of neurons in the hidden layer and the choice of the training algorithm, based on the forecast quality (nMSE around 0.0137) that reached the best results with Net15_BR. At this stage, several theoretical concepts were applied, showing that the nature and amount of data used require practical tests to guarantee the best performance of the tool. When coupling the neural network trained in the simulation software, we compared its numerical simulation with the results from the conventional method of EWI modeling, ensuring a reliable outcome with this new modeling strategy. We also compared the simulation time between these methods, in which the neural network is fast to predict the necessary adjustments to $\mathrm{Kr}$, not increasing new calculations to the production simulation, unlike geochemical modeling, thus reducing the simulation time by an average of $90 \%$. The UNISIMII benchmark and its economic scenario provided the optimization of seawater injection and EWI. At this step, the NPV of the field was maximized using the flow and pressure conditions of the wells and the salinity of the water injection (in the case with EWI) as adjustable variables. The results showed that the injection with EWI had a positive effect on the final production profit, with an increase of 49.62 million dollars (without considering additional Capex due to EWI implementation). We compared the accumulated production, in which the projected water injection increased oil recovery by about $8.7 \%$ with the same injected amount and reduced the accumulated water production by around $52 \%$, compared to the seawater injection. EWI avoided excessive water production and increased the volume of oil recovered. The EWI-500 (500\% base value increase) case is the only that has NPV less than seawater injection; this guarantees the application of the advanced method with a high-cost margin. We emphasize that although the economic attributes used are reliable, they do not represent a real production scenario, which certainly has other investments and revenues considered. The optimization results converged to use higher concentrations of sulfate and calcium, showing the importance of investigating the injection with a higher salinity range, but respecting the technical or economic limits. The increase in the $\mathrm{Kr}$ of the oil, reduction in the $\mathrm{Kr}$ of the water, and a decrease in the residual oil saturation confirmed the Kr changes to more water-wet conditions. These results in $\mathrm{Kr}$ corroborate other studies applied to the EWI method, reinforcing the advantages of controlling salinity for managing fluids displacement in the reservoir.

Acknowledgments. The authors would like to thank $L A S G$ (Laboratory of Petroleum Reservoir Simulation and Management), InTRA (Integrated Technology for Rock and Fluid Analysis) and Escola Politécnica of the Universidade de Sao Paulo. This work was conducted with the ongoing Project registered as "Projeto de Molhabilidade e Propriedades Petrofísicas de Rochas Carbonáticas e sua Relação com a Recuperação de Hidrocarbonetos" (USP/Petrobras/ANP) funded by Petrobras, under the ANP R\&D levy as "Compromisso de Investimentos com Pesquisa e Desenvolvimento". The authors would also like to thank FAPESP (the State of São Paulo Research Foundation), and $C M G^{\circledR}$ and MATLAB ${ }^{\circledR}$ for software licenses.

\section{References}

Adegbite J.O., Al-Shalabi E.W., Ghosh B. (2017) Modeling the effect of engineered water injection on oil recovery from carbonate cores, in: SPE International Conference on Oilfield Chemistry, Society of Petroleum Engineers, pp. 1-33. https://doi.org/10.2118/184505-MS. 
Adegbite J.O., Al-Shalabi E.W. (2020) Optimization of engineered water injection performance in heterogeneous carbonates: a numerical study on a sector model, J. Petrol. Explor. Prod. Technol. 10, 3803-3826. https://doi.org/10.1007/ s13202-020-00912-6.

Bernard G.G. (1967) Effect of floodwater salinity on recovery of oil from cores containing clays, in: Society of Petroleum Engineers - SPE California Regional Meeting, CRM. https://doi.org/10.2523/1725-ms.

Bidhendi M.M., Garcia-Olvera G., Morin B., Oakey J.S., Alvarado V. (2018) Interfacial viscoelasticity of crude oil/brine: An alternative enhanced-oil-recovery mechanism in smart waterflooding, SPE J. 23, 03, 0803-0818. https://doi.org/10.2118/169127-pa.

Bourbiaux B. (2020) Low salinity effects on oil recovery performance: underlying physical mechanisms and practical assessment, Oil Gas Sci. Technol. - Rev. IFP Energies nouvelles 75, 37. https://doi.org/10.2516/ogst/2020030.

Breitenbach E.A. (1991) Reservoir simulation: State of the art, J. Petrol. Technol. 43, 09, 1033-1036.

Brooks R.H., Corey A.T. (1964) Hydraulic properties of porous media, Hydrology Papers, no. 3, Colorado State University.

Burden F., Winkler D. (2008) Bayesian regularization of neural networks, Methods Mol. Biol. 458, 25-44.

Correia M., Hohendorff J., Gaspar A.T.F.S., Schiozer D. (2015) UNISIM-II-D: Benchmark case proposal based on a carbonate reservoir, in: SPE Latin American and Caribbean Petroleum Engineering Conference Held in Quito, Ecuador 1, 18-20. https://doi.org/10.2118/177140-ms.

Dake L.P. (2015) Fundamentals of reservoir engineering, Elsevier, Netherlands, pp. 1-498. https://doi.org/10.1016/ B978-0-08-098206-9.00004-X.

Dang C., Nghiem L., Nguyen N., Chen Z., Nguyen Q. (2015) Modeling and optimization of low salinity waterflood, in: $S P E$ Reservoir Simulation Symposium, Houston, Texas, USA, pp. 1-10. https://doi.org/10.2118/173194-ms.

Dang C., Nghiem L., Nguyen N., Chen Z., Nguyen Q. (2016) Mechanistic modeling of low salinity water flooding, J. Petrol. Sci. Eng. 146, 191-209. https://doi.org/10.1016/j. petrol.2016.04.024.

Dang C.T.Q., Nghiem L.X., Chen Z.J., Nguyen Q.P. (2013) Modeling low salinity waterflooding: Ion exchange, geochemistry and wettability alteration, in: SPE Annual Technical Conference and Exhibition, New Orleans, Louisiana, USA, pp. 1-22. https://doi.org/10.2118/166447-ms.

Fabbri C., de-Loubens R., Skauge A., Hamon G., Bourgeois M. (2020) Effect of initial water flooding on the performance of polymer flooding for heavy oil production, Oil Gas Sci. Technol. - Rev. IFP Energies nouvelles 75, 19. https://doi. org $/ 10.2516 /$ ogst $/ 2020008$.

Fathi S.J., Austad T., Strand S. (2011) Water-based enhanced oil recovery (EOR) by "smart water": Optimal ionic composition for EOR in carbonates, Energy Fuels 25, 11, 5173-5179. https://doi.org/10.1021/ef201019k.

Fjelde I., Asen S.M., Omekeh A.V. (2012) Low salinity water flooding experiments and interpretation by simulations, in: SPE Improve Oil Recovery Symposium, Tulsa, Oklahoma, USA, pp. 1-22. https://doi.org/10.2118/154142-ms.

Ghahramani Z. (2004) Unsupervised Learning, in: Advanced Lectures on Machine Learning: ML Summer Schools 2003, Springer, Berlin Heidelberg, pp. 72-112. https://doi.org/ 10.1007/978-3-540-28650-9_5.

Ghosh B., Sun L., Osisanya S. (2016) Smart-water EOR made smarter a laboratory development, in: International Petro- leum Technology Conference, Bangkok, Thailand, pp. 1-13. https://doi.org/10.2523/18988-ms.

Hayashi S.H.D. (2006) Value of flexibility and information in field development by modules, Master Thesis, Faculty of Mechanical Engineering, State University of Campinas, 138 p. (in Portuguese).

Hirasaki G., Zhang D.L., Rice U. (2004) Surface chemistry of oil recovery from fractured, oil-wet, carbonate formations, in: International Symposium on Oilfield Chemistry, Houston, Texas, USA, pp. 151-163. https://doi.org/10.2118/88365-pa. Jerauld G.R., Lin C.Y., Webb K.J., Seccombe J.C. (2006) Modeling low-salinity waterflooding, in: SPE Annual Technical Conference and Exhibition, San Antonio, Texas, USA, pp. 1-13. https://doi.org/10.1002/app.30886.

Kayri M. (2016) Predictive abilities of Bayesian regularization and levenberg-marquardt algorithms in artificial neural networks: A comparative empirical study on social data, Math. Comput. Appl. 21, 2, 1-11. https://doi.org/10.3390/ mca21020020.

Lie K.A. (2012) An Introduction to Reservoir Simulation Using MATLAB/GNU Octave, Vol. 21, Cambridge University Press, pp. 1-659. https://doi.org/10.1016/j.solener.2019.02.027.

Mohaghegh S. (2000) Virtual-intelligence applications in Petroleum Engineering: Part 1 - Artificial Neural Networks, $J$. Petrol. Technol. 52, 09, 64-73, 64-71.

Morrow N.R., Tang G.Q., Valat M., Xie X. (1998) Prospects of improved oil recovery related to wettability and brine composition, J. Petrol. Sci. Eng. 20, 3-4, 267-276. https://doi. org/10.1016/S0920-4105(98)00030-8.

Mustafiz S., Islam M.R. (2008) State-of-the-art petroleum reservoir simulation, Petrol. Sci. Technol. 26, 10-11, 13031329. https://doi.org/10.1080/10916460701834036.

Rajasekaran S., Pai G.A.V. (2017) Neural networks, fuzzy systems, and evolutionary algorithms: Synthesis and applications, PHI Learning Pvt. Ltd, New Delhi, India, pp. 1-442.

Reginato L.F., Carneiro C.C., Gioria R.S., Sampaio M.A. (2019) Prediction of wettability alteration using the artificial neural networks in the salinity control of water injection in carbonate reservoirs, Offshore Technology Conference Brazil, Rio de Janeiro, Brazil, pp. 1-17. https://doi.org/10.4043/29916-ms.

Saikia B.D., Mahadevan J., Rao D.N. (2018) Exploring mechanisms for wettability alteration in low-salinity waterfloods in carbonate rocks, J. Petrol. Sci. Eng. 164, 595-602. https://doi.org/10.1016/j.petrol.2017.12.056.

Sampaio M.A., Barreto C.E.A.G., Schiozer D.J. (2015) Assisted optimization method for comparison between conventional and intelligent producers considering uncertainties. J. Petrol. Sci. Eng. 133, 268-279. https://doi.org/10.1016/j.petrol. 2015.06.023.

Seethepalli A., Adibhatla B., Mohanty K.K. (2004) Physicochemical interactions during surfactant flooding of fractured carbonate reservoirs, SPE J. 9, 04, 411-418. https://doi.org/ 10.2118/89423-pa.

Shobha G., Rangaswamy S. (2018) Machine Learning, in: Handbook of Statistics, 1st ed., Vol. 38, Elsevier B.V., pp. 1-32. https://doi.org/10.1016/bs.host.2018.07.004.

Strand S., Høgnesen E.J., Austad T. (2006) Wettability alteration of carbonates - Effects of potential determining ions $\left(\mathrm{Ca}^{2+}\right.$ and $\left.\mathrm{SO}_{4}{ }^{2-}\right)$ and temperature, Colloids Surf. A Physicochem. Eng. Aspects 275, 1-3, 1-10. https://doi.org/ 10.1016/j.colsurfa.2005.10.061.

Strik D.P.B.T.B., Domnanovich A.M., Zani L., Braun R., Holubar P. (2005) Prediction of trace compounds in biogas 
from anaerobic digestion using the MATLAB Neural Network Toolbox, Environ. Model. Softw. 20, 6, 803-810. https://doi. org/10.1016/j.envsoft.2004.09.006.

Talabis M.R.M., McPherson R., Miyamoto I., Martin J.L., Kaye D. (2015) Chapter 1 - Analytics defined, in: Information Security Analytics, Syngress, Boston, USA, pp. 1-12.

Webb K.J., Black C.J.J., Al-Ajeel H., Members S. (2004) Low salinity oil recovery-log-inject-log, in: Fourteenth Symposium on Improved Oil Recovery, pp. 17-21. https://doi.org/ 10.2118/89379-MS.

Xiao R., Gupta R., Glotzbach R.C., Sinha S., Teletzke G.F. (2018) Evaluation of low-salinity waterflooding in Middle East carbonate reservoirs using a novel, field-representative coreflood method, J. Petrol. Sci. Eng. 163, 683-690. https://doi. org/10.1016/j.petrol.2017.10.070.

Yousef A.A., Al-Saleh S., Al-Jawfi M.S. (2011) Smart waterflooding for carbonate reservoirs: salinity and role of ions, in: SPE Middle East Oil and Gas Show and Conference Held in Manama, Bahrain, September, pp. 1-11. https://doi.org/ 10.2118/141082-ms.
Yousef A.A., Al-Saleh S., Al-Kaabi A., Al-Jawfi M., Aramco S. (2010) Laboratory investigation of novel oil recovery method for carbonate reservoirs, Canadian Unconventional Resources \&6 International Petroleum Conference, Calgary, Alberta, Canada, pp. 1-35. https://doi.org/10.2118/137634-ms.

Zaheri S.H., Khalili H., Sharifi M. (2020) Experimental investigation of water composition and salinity effect on the oil recovery in carbonate reservoirs, Oil Gas Sci. Technol. - Rev. IFP Energies nouvelles 75, 21. https://doi.org/10.2516/ogst/2020010.

Zhang P., Tweheyo M.T., Austad T. (2007) Wettability alteration and improved oil recovery by spontaneous imbibition of seawater into chalk: Impact of the potential determining ions $\mathrm{Ca}^{2+}, \mathrm{Mg}^{2+}$, and $\mathrm{SO}_{4}{ }^{2-}$, Colloids Surf. A Physicochem. Eng. Aspects 301, 199-208. https://doi.org/10.1016/j.colsurfa. 2006.12.058.

Zhang T., Li Y., Li C., Sun S. (2020) Effect of salinity on oil production: review on low salinity waterflooding mechanisms and exploratory study on pipeline scaling, Oil Gas Sci. Technol. - Rev. IFP Energies nouvelles 75, 50. https://doi. org/10.2516/ogst/2020045. 